\title{
Mitral regurgitation secondary to ventricular remodelling post myocardial infarction - an echocardiographic study
}

\author{
N Thakur ${ }^{1 *}$, A lonac ${ }^{1,2}$ \\ From International Conference for Healthcare and Medical Students 2011 \\ Dublin, Ireland. 4-5 November 2011
}

\section{Introduction}

To evaluate the incidence and mechanism of mitral regurgitation $[\mathrm{MR}]$ as a complication in the evolution of myocardial infarction [MI]. Patient population: 95 patients diagnosed on the basis of clinical, electrocardiographic and coronary-angiographic data with coronary artery disease [CAD] with a history of MI with haemodynamically significant MR ( $>$ /=grade II).

- All patients were treated in accordance with standard therapy for CAD and heart failure

- 56 Patients with PTCA of the obstructed coronary artery

- 28 Patients treated with CABG out of these 19 patients with mitral valvuloplasty

Criteria for exclusion from the study: patients with organic MR (mitral valve modified as a result of rheumatic fever, infectious endocarditis or degeneration) or with myxomatous mitral valve prolapse.

\section{Methods}

Transthoracic echocardiography [TTE] for all patients and transoesophageal echocardiography for 75 patients.

\section{Results}

Sixty eight patients had grade II MR and twenty seven grade III MR. The aetiology of MR was:

- Papillary muscle rupture -1 patient

- Papillary muscle ischaemia (inferior or posterior MI) 15 patients

- Dilatation and remodeling of left ventricle [LV] - 58 patients (13 out of these 58 patients had LV aneurysms)

"Victor Babes" University of Medicine and Pharmacy, Timisoara, Romania Full list of author information is available at the end of the article
- Mixed mechanism (papillary muscle ischaemia and LV dilatation) - 21 patients

\section{Conclusions}

MR appears frequently in the evolution of patients with MI, even in patients subjected to a standard line of treatment. Echocardiography is a very important tool for the evaluation of severity and more importantly, that of aetiology. Understanding of the mechanism of MR offers the possibility to find a correct treatment option and where necessary, an optimal surgical intervention.

Author details

"Victor Babes" University of Medicine and Pharmacy, Timisoara, Romania.

${ }^{2}$ Timisoara Institute of Cardiovascular Medicine, Romania.

Published: 9 July 2012

doi:10.1186/1753-6561-6-S4-P24

Cite this article as: Thakur and lonac: Mitral regurgitation secondary to ventricular remodelling post myocardial infarction - an

echocardiographic study. BMC Proceedings 2012 6(Suppl 4):P24.

Submit your next manuscript to BioMed Central and take full advantage of:

- Convenient online submission

- Thorough peer review

- No space constraints or color figure charges

- Immediate publication on acceptance

- Inclusion in PubMed, CAS, Scopus and Google Scholar

- Research which is freely available for redistribution 